\title{
The value of lymph node ratio and total number of lymph nodes examined for resected pancreatic signet ring cell carcinoma: a retrospective cohort study
}

\section{Chao Ren}

Xi'an Jiaotong University Medical College First Affiliated Hospital

\section{Feng Xue}

First Affiliated Hospital of Xi'an Medical University

\section{Yinying Wu}

First Affiliated Hospital of Xi'an Medical University

Zheng Wang ( $\sim$ zheng.wang11@mail.xjtu.edu.cn )

First Affiliated Hospital of Xi'an Medical University

\section{Research}

Keywords: Pancreatic signet ring cell carcinoma, lymph node ratio, independent factor, total number of lymph nodes examined

Posted Date: October 30th, 2020

DOI: https://doi.org/10.21203/rs.3.rs-80692/v1

License: (c) (i) This work is licensed under a Creative Commons Attribution 4.0 International License.

Read Full License 


\section{Abstract}

Background-Pancreatic signet ring cell carcinoma (SRCC) was an exceedingly rare histological subtype of pancreatic cancer. Previous studies focused on the trends of incidence and independent predictors of pancreatic SRCC. Our objectives of the study was to analyze the prognostic value of lymph node ratio (LNR) and explore the minimal number of lymph nodes examined to accurately evaluate the $\mathrm{N}$ stage in resected pancreatic signet ring cell carcinoma.

Method-The data diagnosed from January 1, 1990 to December 31, 2016 constituted the study cohort from the Surveillance, Epidemiology, and End Results(SEER) registry. We calculated overall survival (OS) of these patients using Kaplan-Meier analysis and Cox proportional hazards model and used receiveroperating characteristic curve (ROC) analysis to investigate the discriminatory ability of the total number of lymph nodes examined(TNLE) relative to whether lymph node metastasis.

Results-The median number of lymph nodes examined among 120 patients of resected pancreatic SRCC was 14 (interquartile range, 6.25 to 20.0).According to the univariate analysis of overall survival(OS) result, age, grade, chemotherapy, LNR and TNLE were significantly different $(P<0.05)$.Multivariate survival analysis showed that $L N R$ and grade were the independent prognostic indicators after pancreatic SRCC resection for OS. TNLE $\geq 8$ showed the highest discriminatory power to evaluate whether the lymph node metastasis (AUC 0.656, 95\% Cl 0.564-0.741, Youden index 0.2533 , sensitivity $78.67 \%$, specificity $46.67 \%, P=0.003$ )

Conclusion-Our study indicated that LNR was a valuable independent prognostic factor for resected pancreatic SRCC. Regional lymphadenectomy of at least 8 lymph nodes was necessary to stage patients accurately. Enough number lymph nodes examined was necessary for the clinicians to accurately predict the significance of LNR in resected pancreatic SRCC.

\section{Introduction}

Pancreatic signet ring cell carcinoma (SRCC) is a mucin-secreting adenocarcinoma that contains abundant intracytoplasmic mucin and pushes the nucleus to one side of the cell[1].Signet ring cell carcinoma (SRCC) was mostly occurred in the digestive system and the most common sites are the stomach which account for $15.1-28.2 \%$ of primary gastric cancer[2-4], occasionally occurring in the colorectal, bile cyst ,breast, bladder, prostate, and lung, whereas primary pancreatic SRCC is extremely rare. Nowadays, just 12 case reports have been published in the English literature of primary SRCC of the pancreas[5-16].Previously a large population-based cohort of 497 patients with pancreatic SRCC focused on independent predictors, with the 1-, 2-, and 5-year OS rates of $17 \%, 9 \%$, and $4 \%$, respectively, which showed a very poor survival[17].

The lymph node ratio (LNR) was defined as the ratio of number of metastatic lymph nodes relative to the total number of LN examined (TNLE). In the 8th edition of TNM staging guidelines[18, 19],N stage has been further classified as N0 (no nodal metastasis), N1(1-3 LNM), and N2 ( $\geq 4$ LNM) while N stage is 
just classified as N0 (no nodal metastasis), N1( $\geq 1$ LNM) in the 6th edition of TNM staging guidelines. Several studies demonstrated that LNR had been considered as a more powerful predictor of survival in patients than positive lymph node[20-22]. However, it remains unclear that determine LNR segmentation points and elaborate the role of LNR in evaluating survival and prognosis of patients with pancreatic SRCC. TNLE is necessary to evaluate accurately the $\mathrm{N}$ stage, but until now no study has reported the minimal number of TNLM of resected pancreatic signet ring cell carcinoma.

In this study, we analyze the significance of LNR and TNLE through extracting large sample of patients with resected pancreatic SRCC from Surveillance, Epidemiology, and End Results (SEER) database registry of the National Cancer Institute. The aim was to retrospectively study the relationship between LNR and the prognosis of pancreatic SRCC, to find the independent factors of pancreatic SRCC, and to explore the minimal number of TNLM to accurately evaluate the $\mathrm{N}$ stage.

\section{Methods}

\subsection{Patients}

The data used in this study were retrieved from SEER database registry of National Cancer Institute. All the data accessed from the SEER database were freely available. Therefore, this study does not require institutional review board approval for use of the SEER database. The permission was obtained to access the research data files (reference number 10918-Nov2019).

In order to identify all eligible cases, the following including criteria were applied: (i)all patients were diagnosed as International Classification of Diseases for Oncology, Third Edition (ICD-0-3), histology code: 8490[17]; and the ICD-0-3 site code C25.1, C25.2, C25.3,C25.8 and C25.9. (ii) active follow-up of patients (diagnosis not obtained from autopsy or death certificate) (iii) positive histology confirmation, surgical resection and no distant metastases(M0 stage) (iv)Complete data of the number of lymph nodes examined and positive lymph nodes $(\mathrm{v})$ In the data of complete TNM staging, we choose the 6th edition (2004-2015) of TNM staging. Based on above criteria, a total of 120 patients with pancreatic signet ring cell carcinoma diagnosed from January 1, 1990 to December 31, 2016 were enrolled in our study cohort.

\subsection{Data collection}

In our study, the following demographic, clinicopathologic characteristics were reviewed: age, race, sex, tumor location, grade, TNM staging, T stage, N stage(6th), nodal status, radiotherapy, chemotherapy, total number of lymph nodes examined, LNR, survival months, and vital status. Age at diagnosis was divided into two groups (less than 75 years and at least 75 years).For the tumor grade status, we combined "poorly differentiated" and "undifferentiated".For the T stage, patients in the "T1 stage" and "T2 stage" were clustered as "T1+T2", while patients in the "T3 stage" and "T4 stage" as "T3+T4". The outcome was overall survival(OS), which was defined as interval from date of diagnosis to date of death (all causes) or last follow-up. X-tile is a bio-informatics tool for biomarker assessment and outcome-based cut-point optimization[23].X-tile has been widely used into decide the cutoff value of the biomarker and prognosis 
factors[24-26].The optimal cutoff value of lymph nodes ratio was 0.20 and the optimal cutoff value of TNLE was 8 , which were both analyzed by X-tile software.(Figure 1,2)

\subsection{Statistical analysis}

All statistical analyses were performed by SPSS 25.0 statistical package (IBM Corporation, Armonk, NY, USA). Continuous data were expressed in the form of medians with interquartile range (IQR) and MannWhitney $U$ tests was used to compared these data. Categorical data were compared using $x^{2}$ test. The OS were compared by Kaplan-Meier curves in univariate analysis using the log-rank test via SPSS and GraphPad Prism 8.0 Software (GraphPad Software Inc. San Diego, CA, USA). The multivariate analyses and hazard ratios (HRs) were used by Cox proportional hazards regression model to find its independent prognostic risks. The cutoff value of variable was determined by X-tile software (Yale University, New Haven, CT, USA). The receiver-operating characteristic curve (ROC) analysis was used to investigate the discriminatory ability of TNLE relative to whether lymph node metastasis[27, 28]. The resulting hazard ratios $(\mathrm{HR})$ and $95 \%$ confidential intervals $(95 \% \mathrm{Cl})$ were presented. All tests were two-sided and P-value $<0.05$ was considered statistically significant.

\section{Results}

\subsection{Clinicopathological characteristics}

Of 859 patients identified with pancreatic SRCC, 120 patients were finally included in our study. There were 64 males (53.3\%) and 56 females (46.7\%) with the median age of was 67 years (IQR,58.3-75.0 years). Tumor was located at pancreatic head (12.5\%), at body or tail(79.2\%). Poorly differentiation and undifferentiation ( $n=95,79.2 \%$ ) was the most common tumor grade, followed by moderate differentiation ( $n=18,15.0 \%)$. More than half of patients $(75 ; 62.5 \%)$ had lymph node metastasis was compared with $45(37.5 \%)$ patients without metastasis. 41 patients $(22.6 \%)$ received radiotherapy while 64 patients $(53.3 \%)$ had received chemotherapy. 1-7 lymph nodes were examined in 37 patients(30.8\%) and at least 8 lymph nodes were examined in 83 patients(69.2\%). The detailed baseline characteristics were displayed in Table 1.

\subsection{Correlations between LNR and clinicopathologic characteristics}

The median LNR of all patients was $0.106($ IQR, $0-0.273)$. We divided the entire cohort into

the low-risk cohort $(L N R<0.20)$ and high-risk cohort $(L N R \geq 0.20)$ according to the result analyzed by $X$-tile software.76 patients were included into the low-risk cohort $(L N R<0.20)$ while 44 patients constitute the high-risk cohort $(L N R \geq 0.20)$.It was statistically significant that $L N R$ was correlated with tumor grade $(P=0.023)$,location $(0.017), N$ stage $(6$ th $)(P<0.001)$ and nodal status $(P<0.001)$.

\subsection{High level of LNR and low level of TNLE is related with poor survival}


As is shown in the figure 1 and figure 2, 8 and 0.20 were the cutoff value of TNLE and LNR respectively. The Kaplan-Meier curves showed that there were significant differences of OS rates of LNR and TNLE $(P<0.05)$.According to the result of OS, it showed that higher level of LNR and low level of TNLE for patients with resected pancreatic signet ring cell carcinoma has a worse survival(Fig. 3A,3B). With the further stratified data analysis, when TNLE was at least 8, LNR was able to distinguish the survival difference of patients with resected pancreatic signet ring cell carcinoma in the OS analysis(Fig. 3C,3D).

\subsection{Prognostic significance of chemotherapy}

In the total cohort, patients with resected pancreatic signet ring cell carcinoma are more likely to acquire chemotherapy(64/120) rather than radiotherapy(41/120). There were no significant differences in OS of radiotherapy $(P>0.05, F i g 4 A)$. The overall median survival time of patients with resected pancreatic signet ring cell carcinoma who do not acquire chemotherapy was just 10 months and who acquire chemotherapy was just 16 months. Chemotherapy can statistically improve survival in OS analyses $(P<0.05$, Fig4B $)$.

\subsection{Univariate and multivariate analyses}

The median OS of pancreatic SRCC was 12 months (IQR,6-29months) and the 1-year ,3-year ,5-year OS rates were $52.4 \%, 20.8 \%$ and $16.6 \%$ respectively. In the univariate analysis, age $(P=0.019)$, grade $(P=$ $0.001)$, chemotherapy $(P=0.009), \operatorname{LNR}(P=0.006), \operatorname{TNLE}(P=0.010)$ were significantly associated with $0 S$, while race, sex, tumor location, TNM staging, $T$ stage, $N$ stage(6th), nodal status, radiotherapy were not significantly related to $O S(P>0.05)$.

Variables that were significantly associated with OS analyzed by multivariate analyses were

selected to be prognostic indicators (Table 3). After adjusting for other risk factors in the model for LNR of multivariate survival analysis, $L N R(P=0.010, H R=1.178,95 \% \mathrm{Cl}: 1.149$ to 2.756$)$ and grade $(P=0.011, H R$ $=2.481,95 \% \mathrm{Cl}: 1.230-5.002)$ were considered as the independent prognostic indicator. In the model for TNLE of multivariate analysis, grade $(P=0.010, \mathrm{HR}=2.512,95 \% \mathrm{Cl}: 1.246-5.064)$ was considered as the independent prognostic indicator while $\operatorname{TNLE}(\mathrm{P}=0.060, \mathrm{HR}=0.643,95 \% \mathrm{Cl}: 0.406-1.019)$ was not.

\subsection{Total number of lymph node examined and nodal status}

Total number of lymph node examined and nodal status are important to identify the $\mathrm{N}$ stage. To further clarify the optimal value of TNLE, ROC analysis was used to investigate the discriminatory ability of total number of lymph node examined among the patients who had no LNM(NO), and also patients who had at least $1 \mathrm{LNM}$ (N1 6th). As is shown in the figure 5, TNLE 8 showed the highest discriminatory power(AUC $0.656,95 \% \mathrm{Cl} 0.564-0.741$, Youden index 0.2533 , sensitivity $78.67 \%$, specificity $46.67 \%, P=0.003$ ). Even though in our univariate analysis, $\mathrm{N}$ stage(6th) and nodal status were not prognostic factors (Fig 6A,7A) while TNLE was not the independent prognostic indicator. In the further stratified data analysis, we find that when TNLE was $\geq 8, \mathrm{~N}$ stage(6th),N stage(8th) show their prognostic significance of patients with 
resected pancreatic signet ring cell carcinoma(Fig $6 C, 7 \mathrm{C}, \mathrm{P}<0.05)$. Combined with these above result, 8 was the optimal cutoff value of the number of lymph node examined to identify the $\mathrm{N}$ stage.

\section{Discussion}

Signet ring cell carcinoma (SRCC) of the pancreas was an exceedingly rare histological subtype of pancreatic cancer, accounting for $<1 \%$ of pancreatic cancers[14]. Because of the rarity of histological subtype, previous studies always reported the trends of incidence and predictors of pancreatic SRCC. One SEER analysis[17]firstly study the impact of epidemiological factors and treatment interventions and make stratified analysis of stage (localized/regional $(n=152)$, distant $(n=345))$.

Another analysis[29] focused on trends of incidence and predictors affect the overall survival of patients with SRC in gastrointestinal tract and pancreas. Nowadays, no study has focused on the significance of lymph node ratio and total number of lymph nodes examined of pancreatic SRCC. Our study is the first population-based study reported to address these issues about LNR in patients with resected pancreatic SRCC and sought to determine the minimal number of lymph nodes to decide accurately the $\mathrm{N}$ stage of patients undergoing resection of pancreatic SRCC.

Despite the poor 5-year OS rate(4\%), Mausam et al[17] discovered age, site, stage, and treatment were all independent predictor of pancreatic SRCC. In our study, after surgery performed, the 5-year OS rate of patients with pancreatic SRCC is improved up to $16.6 \%$, which indicates that surgery could obviously improve survival of patients with resectable pancreatic SRCC. In the univariate and multivariate analysis, we confirmed that grade and LNR were the independent indicators which is different from the previous research results.

There was no consensus of standard chemoradiotherapy of pancreatic SRCC. According to the findings of Mausam, external beam radiation therapy could improve patients with resectable pancreatic SRCC. What is more, their researches do not reveal the significance of chemotherapy. In the case report of pancreatic signet ring cell carcinoma, it showed a good response to neoadjuvant gemcitabine monotherapy. For pancreatic SRCC, Kaji et al[12] reported one case that three chemotherapy program was performed following by etoposide and cisplatin (EP therapy),S-1 monotherapy, albumin-bound paclitaxel and gemcitabine. Dheeraj et al[14] reported that borderline resectable disease should still be considered for neoadjuvant chemotherapy to facilitate potential resectability. Based on these findings, we thought that it seems chemotherapy based on gemcitabine could be used as a beneficial attempt for the treatment of patients if patients could tolerate the chemotherapy. In our study cohort, we revealed the prognostic benefit of chemotherapy in resected pancreatic SRCC while radiotherapy was not associated with improved survival. However, how to choose chemotherapy before or after operation and which kind of program of chemotherapy should be further studied.

According to the report of epidemiology of pancreatic cancer[30],pancreatic cancer is mostly diagnosed in elderly individuals aged $>70$ years. Wang et al[31] proposed that age at diagnosis is a negatively independent factor to pancreatic cancer patients and early diagnosis means very important significance 
to improve the survival of pancreatic cancer patients .In one case report, Natesh et al[15] found that poorly differentiated signet ring cell carcinoma of pancreas was delayed because of incorrect diagnosis as chronic pancreatitis and patients died in 8 weeks after diagnosis, which means early diagnosis is important to the physician and the patient. In our analysis, the median age of pancreatic SRCC was 67 years (IQR,58.3-75.0 years), similarly to the previous literature. Age at diagnosis is also a negative risk factor of pancreatic SRCC, which demonstrate that 1-year OS and 3-year OS of patients over 75 years old were just $40.2 \%$ and $12.6 \%$ while 1 -year OS and 3-year OS of patients younger than 75 years old were $56.9 \%$ and $22.3 \%$.

In recent years, LNR has been considered as an independent prognostic predictor of survival in PDAC patients better than positive lymph nodes for patients after resection of pancreatic cancer[32-34].It is not surprising that LNR could be used to assess the survival of resected pancreatic SRCC. But at present, the role of LNR in predicting survival of resected pancreatic SRCC is unclear. It is worthy to set standard on the best cutoff value for LNR and confirm whether LNR is correlated with OS of resected pancreatic SRCC. Our study is the first population-based analysis to describe the value of LNR in resected pancreatic SRCC. In our study, LNR was confirmed as an independent prognostic risk factor in the univariate and multivariate analyses. Using $\mathrm{X}$-tile software, 0.20 was the optimal cutoff value to assess the overall survival.

In the consensus statement by the International Study Group on Pancreatic Surgery (ISGPS),standard lymphadenectomy for PDAC, should regularly provide at least 15 lymph nodes to ensure adequate pathologic staging of the disease[35]. The mean number of LNs resected in patients with pancreatic cancer who underwent standard lymphadenectomy in the randomized controlled trials (RCTs) was 13 to 17[36-38].These above guidelines focus on studying pancreatic adenocarcinoma(PDAC) and there is no previous evidence to decide the optimal cutoff value of total lymph nodes examined in patients resected pancreatic SRCC.X-tile software succeed to find 8 is the optimal cutoff value of the number of lymph nodes examined. Zhang et al[27, 28] used ROC analysis to investigate the minimal number of lymph nodes to evaluate the $\mathrm{N}$ stage and find regional lymphadenectomy of at least 8 lymph nodes was necessary to stage patients accurately. Using the similarly method, our study find TNLE 8 showed the highest discriminatory power to evaluate whether the lymph node metastasis(AUC 0.656, $P=0.003$ ).We successfully draw the conclusion that the minimal TNLE to evaluate the $\mathrm{N}$ stage is at least 8 lymph nodes of resected pancreatic SRCC. Nakul et al [39] discovered that when total number of examined lymph nodes was $\geq 13$, LNR consistently correlated with survival. Furthermore, our study demonstrated that the minimum of TNLE was at least 8 which means once crossing the threshold, LNR was not only able to distinguish the survival difference of patients with resected pancreatic SRCC but also allows accurate nodal staging. We think enough number lymph nodes examined was necessary for the clinicians to accurately predict the significance of LNR in resected pancreatic SRCC.

Several limitations in the present study should be taken in account. First of all, our study is a small sample size and retrospective research. It could be further proved the conclusion with more prospective, randomized and standard study. Besides, the SEER database only provides information on whether 
radiotherapy and chemotherapy were done, without mentioning data relating to aim (palliative or curative), doses and schemes. These incomplete data limit the further research of chemoradiotherapy in pancreatic SRCC. Furthermore, the missing data of surgical margin and station of lymph node metastasis may seriously affect the number of lymph nodes examined which could confused the surgeon how to use these data.

\section{Conclusion}

To our knowledge, we firstly describe the value of LNR in resected pancreatic SRCC. Our analysis showed age, grade, chemotherapy, LNR and TNLE were risk factors of OS while grade and LNR were independent adverse prognostic factors of patients with pancreatic SRCC. Furthermore, we demonstrated that regional lymphadenectomy of at least 8 lymph nodes is necessary to stage patients accurately and enough number lymph nodes examined was necessary for the clinicians to accurately predict the significance of LNR in resected pancreatic SRCC. Our analysis may be helpful to performing the $\mathrm{N}$ stage and the decision of the clinicians how to perform regional lymphadenectomy.

\section{Abbreviations}

SRCC signet ring cell carcinoma

LNR lymph node ratio

TNLE the total number of lymph node examined

OS overall survival

AUC area under curve

$\mathrm{Cl} \quad$ confidence interval

TNM tumor, node, metastasis

SEER Surveillance, Epidemiology, and End Results

ICD-0-3 International Classification of Diseases for Oncology, Third Edition

IQR interquartile range

HRs hazard ratios (HRs)

ROC receiver-operating characteristic curve

PDAC pancreatic adenocarcinoma

ISGPS the International Study Group on Pancreatic Surgery 
RCTs randomized controlled trials

\section{Declarations}

\subsection{Ethics approval and consent to participate}

The data used in this study were retrieved from SEER database registry of National Cancer Institute. All the data accessed from the SEER database were freely available. Therefore, this study does not require institutional review board approval for use of the SEER database.

\subsection{Consent for publication}

All the data accessed from the SEER database were freely available. Therefore, this study does not require institutional review board approval for use of the SEER database.

\subsection{Availability of data and materials}

The datasets used and/or analysed during the current study are available from the corresponding author on reasonable request.

\subsection{Competing interests}

The authors declare no conflict of interest.

\subsection{Funding}

This study was financially supported by the National Natural Science Foundation of China (NSFC 81872008 to $Z W)$.

\subsection{Author contributions}

Data curation: Chao Ren

Methodology: Chao Ren,Feng Xue, Yinying Wu

Formal analysis: Chao Ren,Feng Xue, Yinying Wu

Writing - original draft: Chao Ren

Supervision: Zheng Wang

Writing - review \& editing: Feng Xue, Yinying Wu囚Zheng Wang

\subsection{Acknowledgements}

Not applicable 


\section{References}

1. Wu SG, Chen XT, Zhang WW, Sun JY, Li FY, He ZY, Pei XQ, Lin Q: Survival in signet ring cell carcinoma varies based on primary tumor location: a Surveillance, Epidemiology, and End Results database analysis.Expert Rev Gastroenterol Hepatol 2018, 12:209-214.

2. Zhang M, Zhu G, Zhang H, Gao H, Xue Y: Clinicopathologic features of gastric carcinoma with signet ring cell histology.J Gastrointest Surg 2010, 14:601-606.

3. Chiu CT, Kuo CJ, Yeh TS, Hsu JT, Liu KH, Yeh CN, Hwang TL, Jan YY, Lin CJ: Early signet ring cell gastric cancer.Dig Dis Sci 2011, 56:1749-1756.

4. Kunisaki C, Shimada H, Nomura M, Matsuda G, Otsuka Y, Akiyama H: Therapeutic strategy for signet ring cell carcinoma of the stomach.Br J Surg 2004, 91:1319-1324.

5. Tracey KJ, O'Brien MJ, Williams LF, Klibaner M, George PK, Saravis CA, Zamcheck N: Signet ring carcinoma of the pancreas, a rare variant with very high CEA values. Immunohistologic comparison with adenocarcinoma.Dig Dis Sci 1984, 29:573-576.

6. Chow LT, Chow WH: Signet-ring mucinous adenocarcinoma of the pancreas. Chin Med Sci J 1994, 9:176-178.

7. Karaahmet F, Basar O, Coban S, Aydoğ G, Yuksel O: Signet Ring Cell Carcinoma of Both Colon and Pancreas.J Gastrointest Cancer 2015, 46:445-446.

8. McArthur CP, Fiorella R, Saran BM: Rare primary signet ring carcinoma of the pancreas.Mo Med 1995, 92:298-302.

9. Nauta S, Knoester I, van Zanten M, van Geenen E: A Patient with Signet Ring Cell Carcinoma of the Pancreas with a Prolonged Course: A Case Report.Journal of the Pancreas 2016, 17:313-315.

10. Terada T: Primary signet-ring cell carcinoma of the pancreas diagnosed by endoscopic retrograde pancreatic duct biopsy: a case report with an immunohistochemical study.Endoscopy 2012, 44 Suppl 2 UCTN:E141-142.

11. Radojkovic M, llic D, llic I: Primary signet ring cell carcinoma of the pancreas with a good response to chemotherapy: case report and literature review.Tumori 2017, 103:e50-e52.

12. Kaji K, Seishima J, Yamato M, Miyazawa M, Komura T, Marukawa Y, Ohta H, Kasashima S, Kawashima A, Yano M, Unoura M: Clinical utility of endoscopic ultrasound-guided fine-needle aspiration in mixed adenoneuroendocrine carcinoma with signet-ring cells of the pancreas: a case report and review of the literature.Clin J Gastroenterol 2016, 9:43-48.

13. Marcy M, Chetaille B, Charafe-Jauffret E, Giovannini M, Delpéro JR, Monges G: [Signet ring cell carcinoma of the pancreas: a case report].Ann Pathol 2002, 22:314-316.

14. Alexander D, Rashid L, Hollis M, Kavuturu S: Primary signet ring cell carcinoma of the pancreatic head: A case report.Clin Case Rep 2019, 7:2235-2238.

15. Yepuri N, Naous R, Richards C, Dhir M, Jain A: Poorly differentiated signet ring cell carcinoma of pancreas masquerading as chronic pancreatitis.J Surg Case Rep 2018, 2018:rjy 218. 
16. Sakai T, Koshita S, Ito K, Kanno Y, Ogawa T, Kusunose H, Masu K, Kawakami Y, Fujii Y, Murabayashi T, et al: Signet-ring Cell Carcinoma Derived from a Main Duct-type Intraductal Papillary Mucinous Neoplasm of the Pancreas: A Case Report with Long-term Follow-up.Intern Med 2018, 57:1093-1099.

17. Patel M, Hans HS, Pan K, Khan H, Donath E, Caldera H: The Impact of Epidemiological Factors and Treatment Interventions on Survival in Patients With Signet Ring Cell Carcinoma of the Pancreas.Am J Clin Oncol 2018, 41:1176-1184.

18. Chun YS, Pawlik TM, Vauthey JN: 8th Edition of the AJCC Cancer Staging Manual: Pancreas and Hepatobiliary Cancers.Ann Surg Oncol 2018, 25:845-847.

19. Strobel O, Hinz U, Gluth A, Hank T, Hackert T, Bergmann F, Werner J, Büchler MW: Pancreatic adenocarcinoma: number of positive nodes allows to distinguish several $\mathbf{N}$ categories.Ann Surg 2015, 261:961-969.

20. Riediger $\mathrm{H}$, Keck T, Wellner U, zur Hausen A, Adam U, Hopt UT, Makowiec F: The lymph node ratio is the strongest prognostic factor after resection of pancreatic cancer.J Gastrointest Surg 2009, 13:1337-1344.

21. Zhan HX, Xu JW, Wang L, Zhang GY, Hu SY: Lymph node ratio is an independent prognostic factor for patients after resection of pancreatic cancer. World J Surg Oncol 2015, 13:105.

22. Zhu F, Wang H, Guirguis A, Ashamalla H: The Value of Total Lymph Nodes Examined and Number of Positive Lymph Nodes in Determining the Role of Adjuvant Radiation in Pancreatic Cancer Patients.Pancreas 2020, 49:435-441.

23. Camp RL, Dolled-Filhart M, Rimm DL: X-tile: a new bio-informatics tool for biomarker assessment and outcome-based cut-point optimization.Clin Cancer Res 2004, 10:7252-7259.

24. Ene-Obong A, Clear AJ, Watt J, Wang J, Fatah R, Riches JC, Marshall JF, Chin-Aleong J, Chelala C, Gribben JG, et al: Activated pancreatic stellate cells sequester CD8+ T cells to reduce their infiltration of the juxtatumoral compartment of pancreatic ductal adenocarcinoma.Gastroenterology 2013, 145:1121-1132.

25. Lv Y, Wang Z, Li K, Wang Q, Bai W, Yuan X, Yu T, Niu J, Yang Z, Zhu X, et al: Risk Stratification based on CLIF Consortium Acute Decompensation score in Patients with Child-Pugh B Cirrhosis and Acute Variceal Bleeding. Hepatology 2020.

26. Wang W, Xu DZ, Li YF, Guan YX, Sun XW, Chen YB, Kesari R, Huang CY, Li W, Zhan YQ, Zhou ZW: Tumor-ratio-metastasis staging system as an alternative to the 7th edition UICC TNM system in gastric cancer after D2 resection-results of a single-institution study of 1343 Chinese patients.Ann Oncol 2011, 22:2049-2056.

27. Zhang XF, Xue F, Dong DH, Lopez-Aguiar AG, Poultsides G, Makris E, Rocha F, Kanji Z, Weber S, Fisher A, et al: New Nodal Staging for Primary Pancreatic Neuroendocrine Tumors: A Multi-institutional and National Data Analysis.Ann Surg 2019.

28. Zhang XF, Xue F, Dong DH, Weiss M, Popescu I, Marques HP, Aldrighetti L, Maithel SK, Pulitano C, Bauer TW, et al: Number and Station of Lymph Node Metastasis After Curative-intent Resection of Intrahepatic Cholangiocarcinoma Impact Prognosis.Ann Surg 2020. 
29. Li H, Zong Z, Zhou T, Sun L, Wang A, Zhang K, Yi C: Trends of incidence and survival in patients with gastroenteropancreatic signet ring cell carcinoma: an analysis from the Surveillance, Epidemiology, and End Results program.J Gastrointest Oncol 2019, 10:979-988.

30. Ilic M, Ilic I: Epidemiology of pancreatic cancer.World J Gastroenterol 2016, 22:9694-9705.

31. Wang H, Liu J, Xia G, Lei S, Huang X, Huang X: Survival of pancreatic cancer patients is negatively correlated with age at diagnosis: a population-based retrospective study.Scientific reports 2020 , 10:7048-7048.

32. Pu N, Li J, Xu Y, Lee W, Fang Y, Han X, Zhao G, Zhang L, Nuerxiati A, Yin H, et al: Comparison of prognostic prediction between nomogram based on lymph node ratio and AJCC 8th staging system for patients with resected pancreatic head carcinoma: a SEER analysis.Cancer Manag Res 2018, 10:227-238.

33. You MS, Lee SH, Choi YH, Shin BS, Paik WH, Ryu JK, Kim YT, Jang DK, Lee JK, Kwon W, et al: Lymph node ratio as valuable predictor in pancreatic cancer treated with $\mathrm{RO}$ resection and adjuvant treatment.BMC Cancer 2019, 19:952.

34. Liu P, Zhang X, Shang Y, Lu L, Cao F, Sun M, Tang Z, Vollmar B, Gong P: Lymph node ratio, but not the total number of examined lymph nodes or lymph node metastasis, is a predictor of overall survival for pancreatic neuroendocrine neoplasms after surgical resection.Oncotarget 2017, 8:89245-89255.

35. Tol JA, Gouma DJ, Bassi C, Dervenis C, Montorsi M, Adham M, Andrén-Sandberg A, Asbun HJ, Bockhorn M, Büchler MW, et al: Definition of a standard lymphadenectomy in surgery for pancreatic ductal adenocarcinoma: a consensus statement by the International Study Group on Pancreatic Surgery (ISGPS).Surgery 2014, 156:591-600.

36. Farnell MB, Pearson RK, Sarr MG, DiMagno EP, Burgart LJ, Dahl TR, Foster N, Sargent DJ: A prospective randomized trial comparing standard pancreatoduodenectomy with pancreatoduodenectomy with extended lymphadenectomy in resectable pancreatic head adenocarcinoma.Surgery 2005, 138:618-628; discussion 628-630.

37. Pedrazzoli S, DiCarlo V, Dionigi R, Mosca F, Pederzoli P, Pasquali C, Klöppel G, Dhaene K, Michelassi F: Standard versus extended lymphadenectomy associated with pancreatoduodenectomy in the surgical treatment of adenocarcinoma of the head of the pancreas: a multicenter, prospective, randomized study. Lymphadenectomy Study Group.Ann Surg 1998, 228:508-517.

38. Yeo CJ, Cameron JL, Lillemoe KD, Sohn TA, Campbell KA, Sauter PK, Coleman J, Abrams RA, Hruban $\mathrm{RH}$ : Pancreaticoduodenectomy with or without distal gastrectomy and extended retroperitoneal lymphadenectomy for periampullary adenocarcinoma, part 2: randomized controlled trial evaluating survival, morbidity, and mortality.Ann Surg 2002, 236:355-366; discussion 366-358.

39. Valsangkar NP, Bush DM, Michaelson JS, Ferrone CR, Wargo JA, Lillemoe KD, Fernández-del Castillo C, Warshaw AL, Thayer SP: N0/N1, PNL, or LNR? The effect of lymph node number on accurate survival prediction in pancreatic ductal adenocarcinoma.J Gastrointest Surg 2013, 17:257-266.

\section{Tables}


Table 1 Clinicopathological characteristics of patients with resected pancreatic signet ring cell carcinoma according to LNR 


\begin{tabular}{|c|c|c|c|c|}
\hline Variables & No.of patients & LNR $<0.20$ & $L N R \geq 0.20$ & P-value \\
\hline \multicolumn{5}{|l|}{ Age at diagnosis } \\
\hline$<75$ & $88(73.3 \%)$ & 56 & 32 & 0.909 \\
\hline$\geq 75$ & $32(26.7 \%)$ & 20 & 12 & \\
\hline \multicolumn{5}{|l|}{ Race } \\
\hline Black & $13(10.8 \%)$ & 11 & 2 & 0.241 \\
\hline White & $102(85.0 \%)$ & 62 & 40 & \\
\hline Other & $5(4.2 \%)$ & 3 & 2 & \\
\hline \multicolumn{5}{|l|}{ Sex } \\
\hline Male & $64(53.3 \%)$ & 40 & 16 & 0.085 \\
\hline Female & $56(46.7 \%)$ & 36 & 28 & \\
\hline \multicolumn{5}{|l|}{ Location } \\
\hline PancreasHead & $15(12.5 \%)$ & 7 & 8 & 0.017 \\
\hline PancreasBodyTail & $95(79.2 \%)$ & 66 & 29 & \\
\hline PancreasOther & $10(8.3 \%)$ & 3 & 7 & \\
\hline \multicolumn{5}{|l|}{ Grade $(n=113)$} \\
\hline Moderately differentiated & $18(15.9 \%)$ & 16 & 2 & 0.023 \\
\hline Poorly differentiated/ & $95(84.1 \%)$ & 58 & 37 & \\
\hline \multicolumn{5}{|l|}{ Undifferentiated } \\
\hline \multicolumn{5}{|c|}{ TNM staging system(6th) $(n=72)$} \\
\hline I & $3(2.5 \%)$ & 3 & 0 & 0.202 \\
\hline II & $64(53.3 \%)$ & 36 & 28 & \\
\hline III & $5(4.2 \%)$ & 4 & 1 & \\
\hline \multicolumn{5}{|l|}{ T stage(6th) } \\
\hline $\mathrm{T} 1+\mathrm{T} 2$ & $12(10.0 \%)$ & 5 & 7 & 0.162 \\
\hline $\mathrm{T} 3+\mathrm{T} 4$ & $60(50.0 \%)$ & 38 & 22 & \\
\hline \multicolumn{5}{|l|}{ N stage(6th) } \\
\hline No & $45(37.5 \%)$ & 45 & 0 & $<0.001$ \\
\hline N1 & $75(62.5 \%)$ & 31 & 44 & \\
\hline
\end{tabular}




\begin{tabular}{|lllll|}
\hline Nodal status & & & & \\
No & $45(37.5 \%)$ & 45 & 0 & $<0.001$ \\
\hline$\geq 4$ positive nodes & $48(40 \%)$ & 25 & 23 & \\
\hline Radiotherapy & $27(22.5 \%)$ & 6 & 21 & \\
\hline No & & & & 0.107 \\
Yes & $79(77.4 \%)$ & 46 & 33 & \\
\hline Chemotherapy & $41(22.6 \%)$ & 30 & 11 & 0.349 \\
\hline No & & & & \\
\hline Yes & $56(46.7 \%)$ & 33 & 23 & \\
\hline Total lymph nodes examined & $64(53.3 \%)$ & 43 & 21 & 0.557 \\
\hline $1-7$ & & & & \\
\hline$\geq 8$ & $37(30.8 \%)$ & 22 & 15 & \\
\hline
\end{tabular}

Note: Bold figures indicate statistical significant $\mathrm{P}<0.05$

Table 2 Univariate analysis of prognostic factors associated with overall survival of patients with resected pancreatic signet ring cell carcinoma Variables 


\begin{tabular}{|c|c|c|c|c|c|}
\hline & $\mathrm{N}$ & $\begin{array}{l}\text { Median } \\
\text { survival } \\
\text { (months) }\end{array}$ & $\begin{array}{l}\text { 1-year } \\
\text { survival } \\
(\%)\end{array}$ & $\begin{array}{l}\text { 3-year survival } \\
(\%)\end{array}$ & $\begin{array}{l}\mathrm{P} \text { - } \\
\text { value }\end{array}$ \\
\hline \multicolumn{6}{|l|}{ Age at diagnosis } \\
\hline$<75$ & 88 & 15 & 56.9 & 22.3 & 0.019 \\
\hline$\geq 75$ & 32 & 8 & 40.2 & 12.6 & \\
\hline \multicolumn{6}{|l|}{ Race } \\
\hline Black & 13 & 17 & 0 & 0 & 0.695 \\
\hline White & 102 & 13 & 52.3 & 19.3 & \\
\hline Other & 5 & 12 & 40.0 & 20.0 & \\
\hline \multicolumn{6}{|l|}{ Sex } \\
\hline Male & 64 & 14 & 50.8 & 22.4 & 0.860 \\
\hline Female & 56 & 13 & 53.7 & 17.0 & \\
\hline \multicolumn{6}{|l|}{ Location } \\
\hline Body/Tail & 15 & 11 & 36.1 & 21.7 & 0.995 \\
\hline Head & 95 & 14 & 55.4 & 19.0 & \\
\hline Other & 10 & 12 & 48.0 & 12.0 & \\
\hline \multicolumn{6}{|l|}{ Grade } \\
\hline Moderately differentiated & 18 & 53 & 80.4 & 51.0 & 0.001 \\
\hline \multicolumn{6}{|l|}{ Undifferentiated } \\
\hline \multicolumn{6}{|l|}{ TNM staging system(6th) } \\
\hline I & 3 & 38 & 66.7 & 33.3 & 0.496 \\
\hline ॥ & 64 & 13 & 52.9 & 25.1 & \\
\hline III & 5 & 12 & 40.0 & 0 & \\
\hline \multicolumn{6}{|l|}{ T stage(6th) } \\
\hline $\mathrm{T} 1+\mathrm{T} 2$ & 12 & 26 & 66.7 & 31.3 & 0.413 \\
\hline $\mathrm{T} 3+\mathrm{T} 4$ & 60 & 12 & 49.7 & 21.5 & \\
\hline \multicolumn{6}{|l|}{$\mathrm{N}$ stage(6th) } \\
\hline NO & 45 & 18 & 65.2 & 22.6 & 0.206 \\
\hline
\end{tabular}




\begin{tabular}{|c|c|c|c|c|c|}
\hline N1 & 75 & 11 & 44.8 & 17.8 & \\
\hline \multicolumn{6}{|l|}{ Nodal status } \\
\hline No & 45 & 18 & 65.2 & 22.6 & 0.254 \\
\hline 1-3 positive nodes & 48 & 11 & 47.1 & 20.9 & \\
\hline$\geq 4$ positive nodes & 27 & 11 & 40.1 & 8.9 & \\
\hline \multicolumn{6}{|l|}{ Radiotherapy } \\
\hline No & 79 & 12 & 50.0 & 19.3 & 0.556 \\
\hline Yes & 41 & 15 & 57.2 & 23.4 & \\
\hline \multicolumn{6}{|l|}{ Chemotherapy } \\
\hline No & 56 & 10 & 41.3 & 11.8 & 0.009 \\
\hline Yes & 64 & 16 & 62.0 & 28.7 & \\
\hline \multicolumn{6}{|l|}{$\begin{array}{l}\text { Total lymph nodes } \\
\text { examined }\end{array}$} \\
\hline $1-7$ & 37 & 10 & 40.9 & 5.8 & 0.010 \\
\hline$\geq 8$ & 83 & 14 & 54.8 & 27.5 & \\
\hline \multicolumn{6}{|l|}{ Lymph node ratio } \\
\hline$<0.20$ & 76 & 17 & 63.3 & 26.9 & 0.006 \\
\hline$\geq 0.20$ & 44 & 9 & 32.9 & 10.1 & \\
\hline
\end{tabular}

Note: Bold figures indicate statistical significant $\mathrm{P}<0.05$

Table 3 Multivariate analysis of prognostic factors associated with overall survival of patients with resected pancreatic signet ring cell carcinoma. 


\begin{tabular}{|llll|}
\hline Variables & HR & $95 \% \mathrm{Cl}$ & P-value \\
\hline Model 1 with TNLE & & & \\
\hline Age $(<75$ vs $\geq 75)$ & 1.586 & $0.983-2.323$ & 0.061 \\
\hline Grade(G2 vs G3/4) & 2.512 & $1.246-5.064$ & $\mathbf{0 . 0 1 0}$ \\
\hline Chemotherapy(yes/no) & 1.510 & $0.981-2.323$ & 0.059 \\
\hline TNLE(<8 vs $\geq 8)$ & 0.643 & $0.406-1.019$ & 0.060 \\
\hline Model 2 with LNR & & & \\
\hline Age( $<75$ vs $\geq 75)$ & 1.570 & $0.978-2.522$ & 0.062 \\
\hline Grade(G2 vs G3/4) & 2.481 & $1.230-5.002$ & $\mathbf{0 . 0 1 1}$ \\
\hline Chemotherapy(yes/no) & 1.485 & $0.970-2.276$ & 0.069 \\
\hline LNR(<0.20 vs $\geq 0.20)$ & 1.780 & $1.149-2.756$ & $\mathbf{0 . 0 1 0}$ \\
\hline
\end{tabular}

Note: Bold figures indicate statistical significant $\mathrm{P}<0.05$

Abbreviations: LNR, lymph node ratio; HR, Hazard risk; $\mathrm{Cl}$, confidence interval; TNLE,Total lymph nodes examined.

\section{Figures}
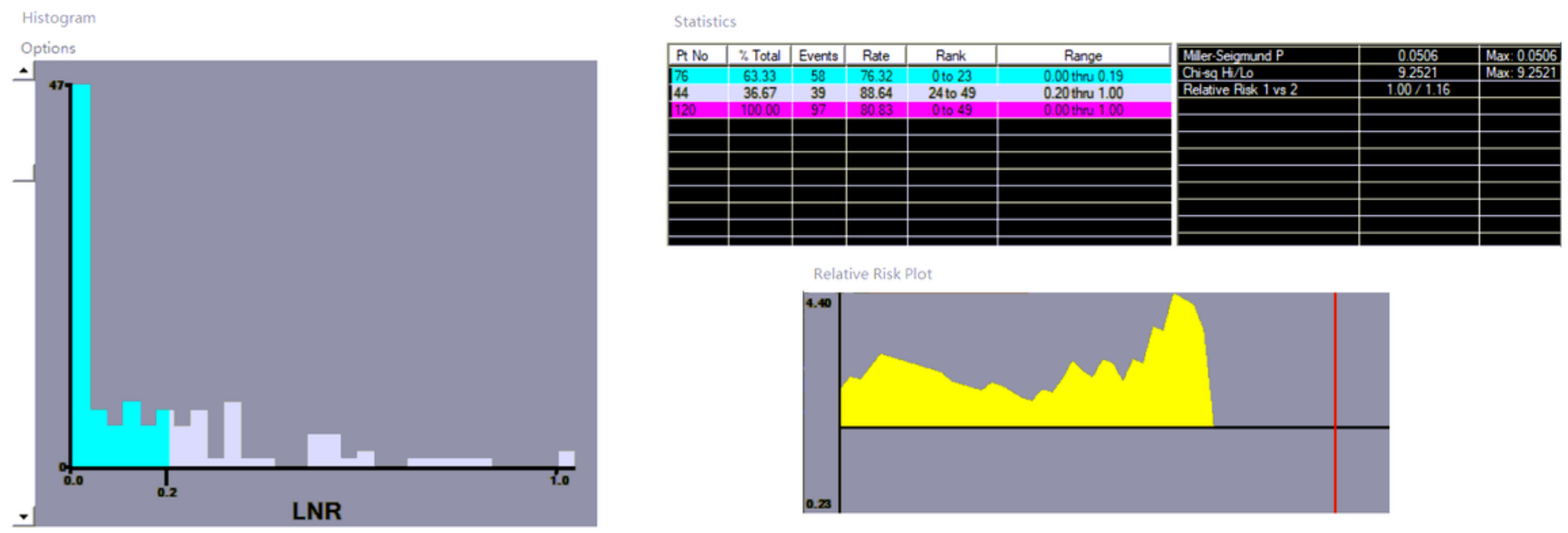

Figure 1

X-tile plots of the cutoff value of lymph node ratio(LNR) on patients with resected pancreatic signet ring cell carcinoma. 

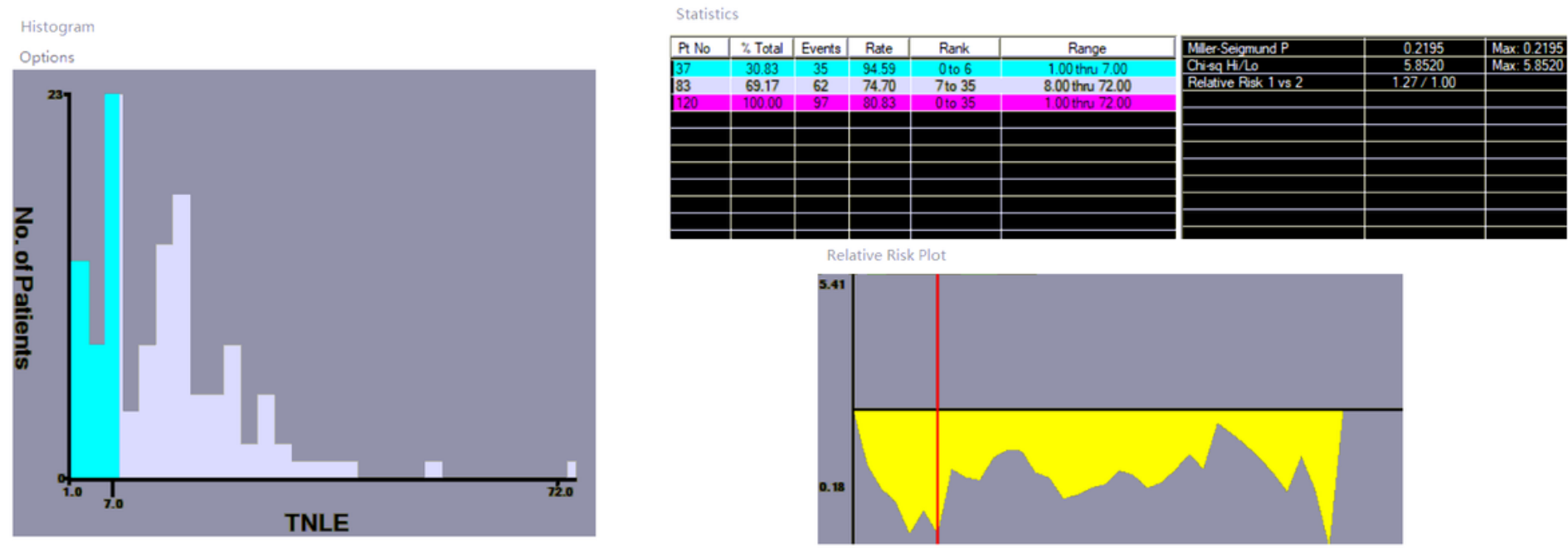

Figure 2

X-tile plots of the cutoff value of the total number of lymph nodes examined(TNLE) on patients with resected pancreatic signet ring cell carcinoma. 
A

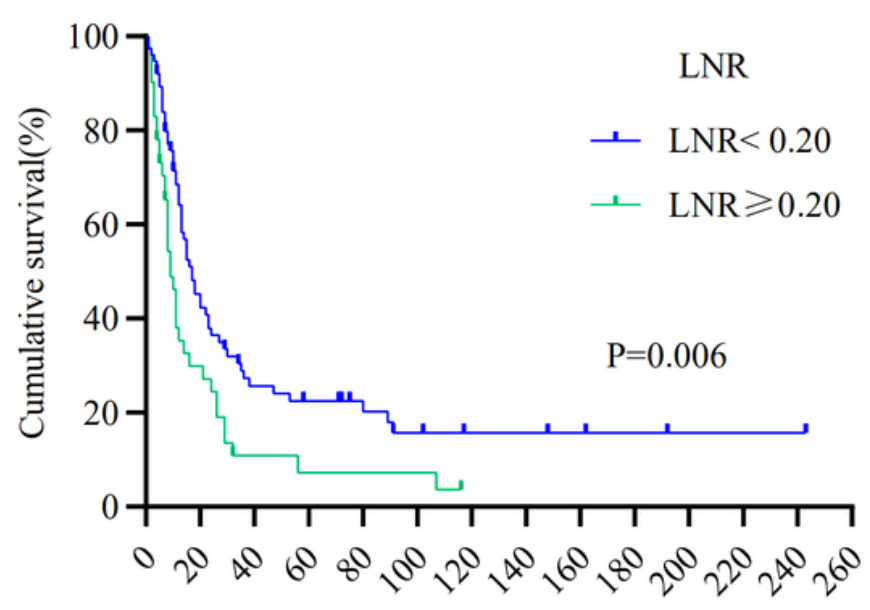

Survival month

C

TNLE $=1-7$

$(\mathrm{N}=37)$

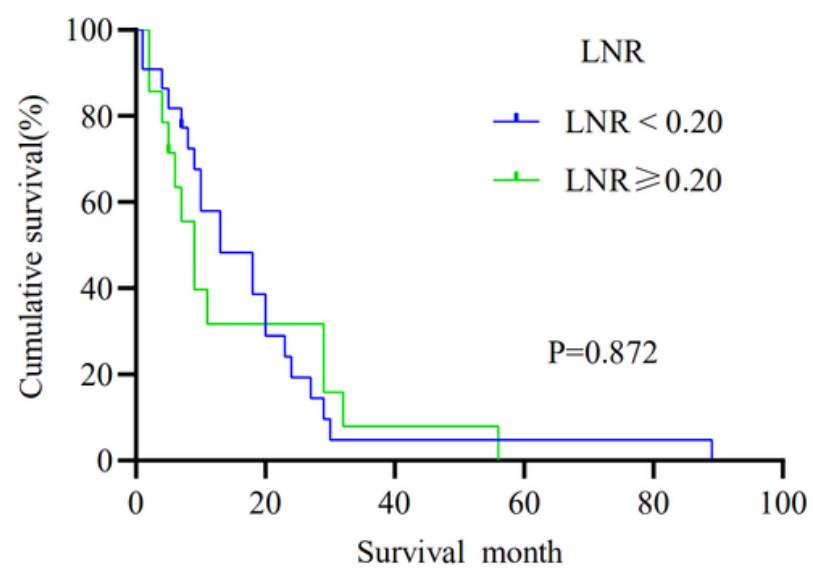

B

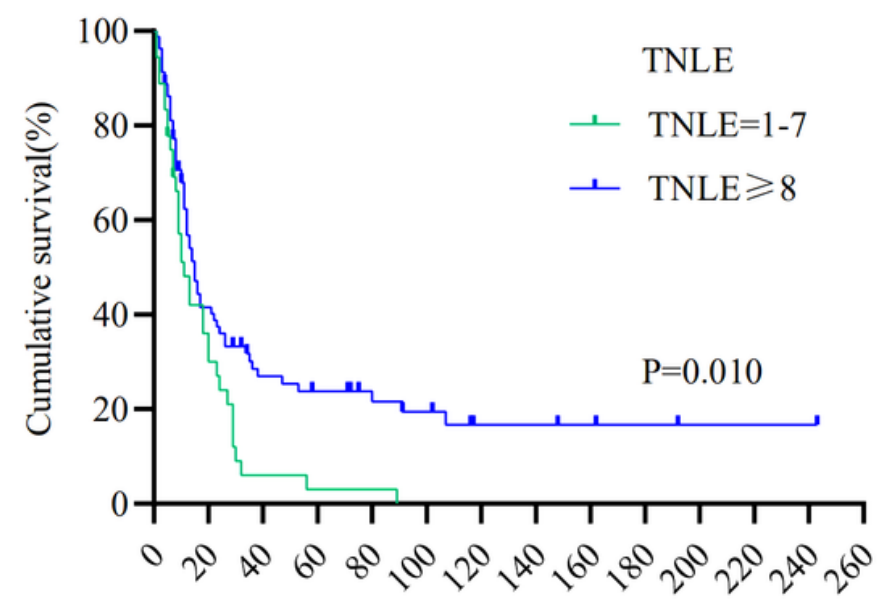

Survival month

D

TNLE $\geqslant 8$

$(\mathrm{N}=83)$

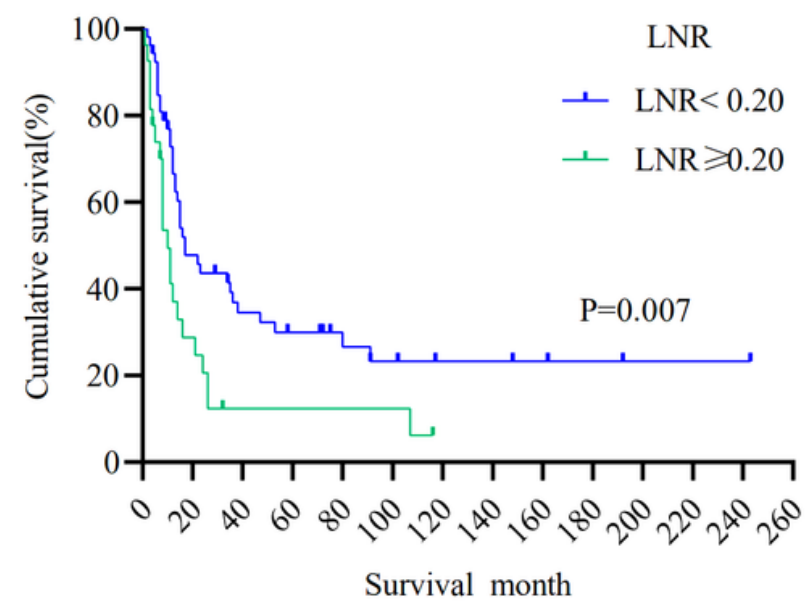

Figure 3

Kaplan-Meier survival curves for patients with resected pancreatic signet ring cell carcinoma according to lymph node ratio(LNR) and the total number of lymph nodes examined(TNLE). 
A

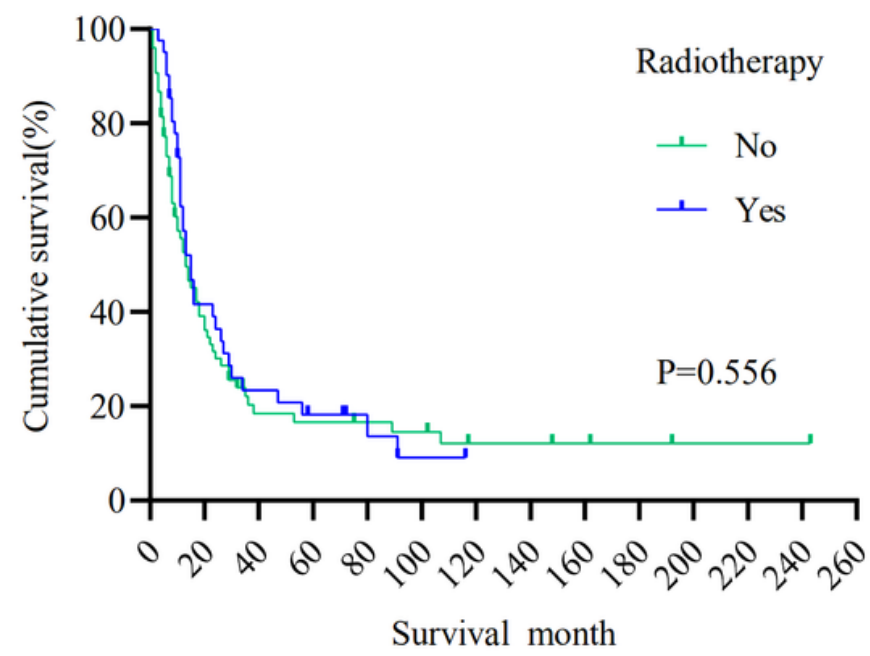

B

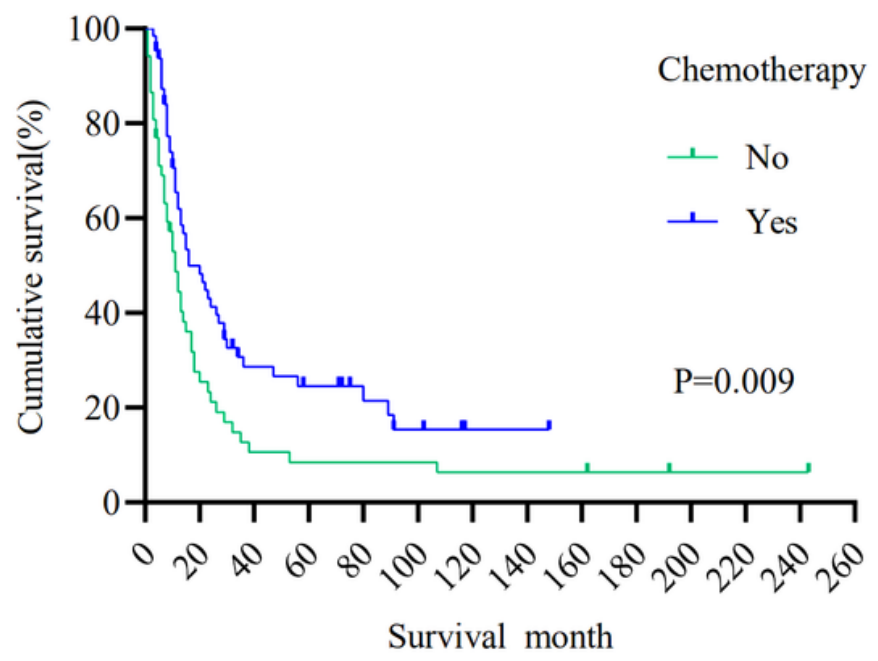

\section{Figure 4}

Kaplan-Meier survival curves of chemotherapy and radiotherapy for patients with resected pancreatic signet ring cell carcinoma 
A

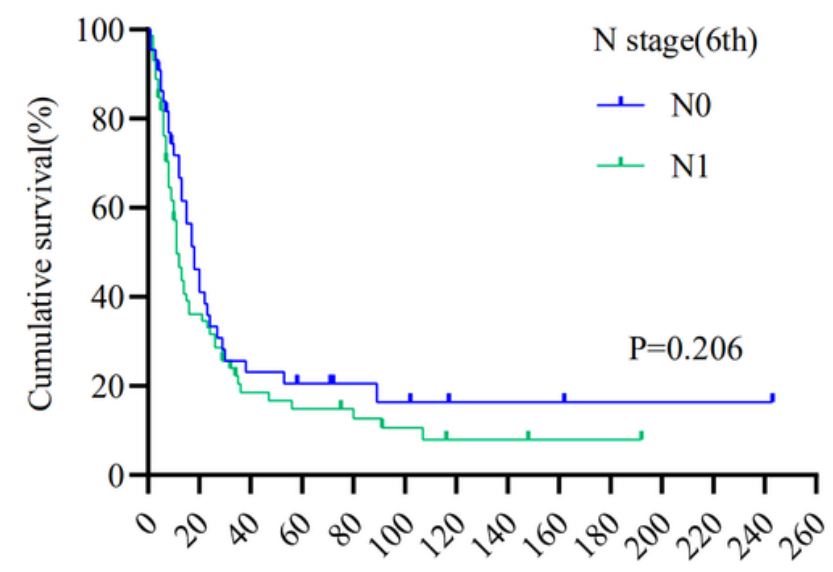

Survival month

B

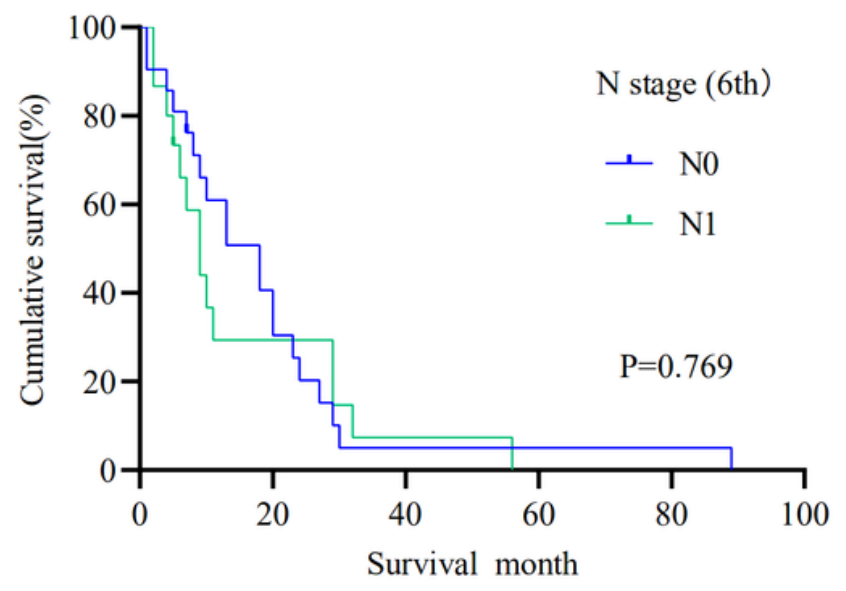

C TNLE $\geqslant 8$

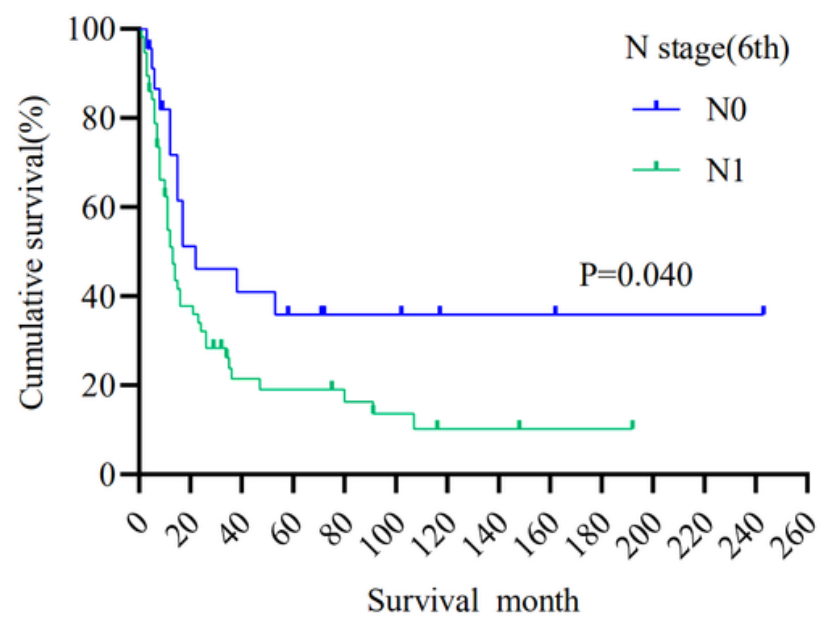

Figure 5

Kaplan-Meier of overall survival analysis of patients with no lymph node metastasis (LNM) and any LNM stratified by TNLE $<8$ or at least 8 . 
A

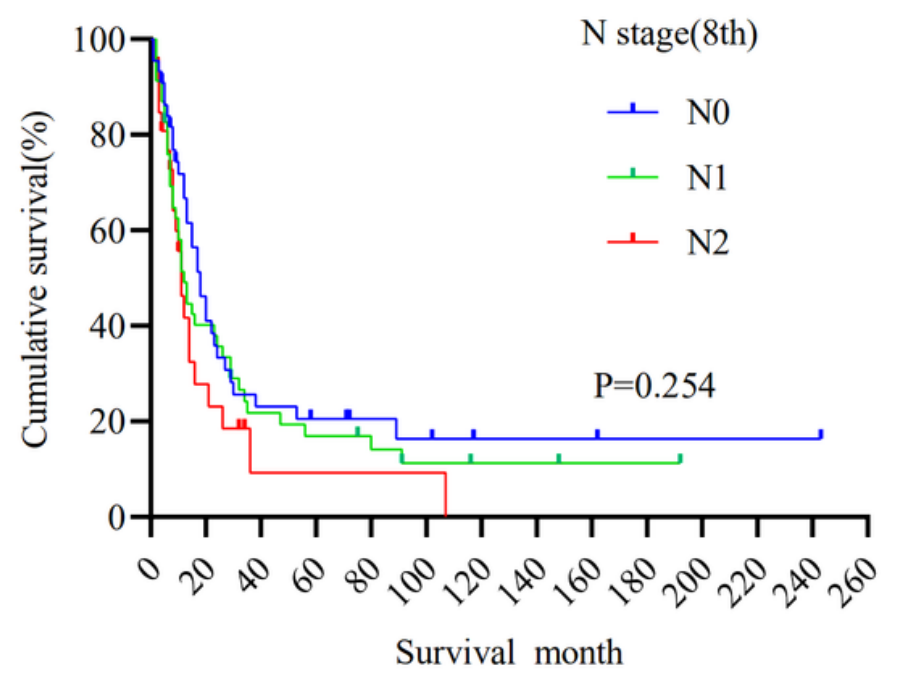

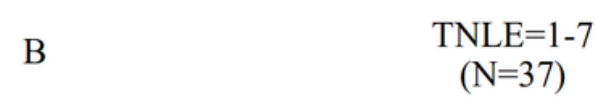

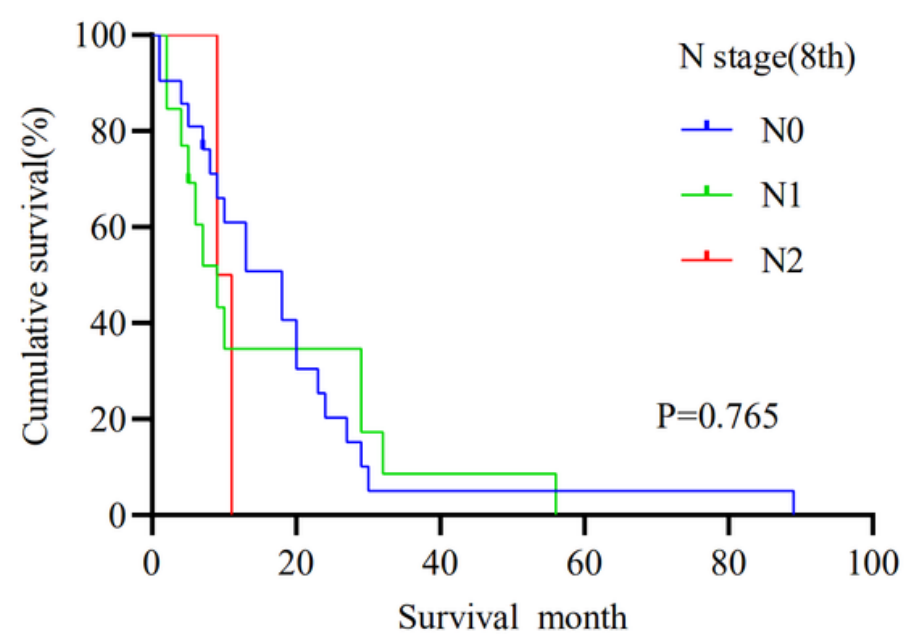

C TNLE $\geqslant 8$

$(\mathrm{N}=83)$

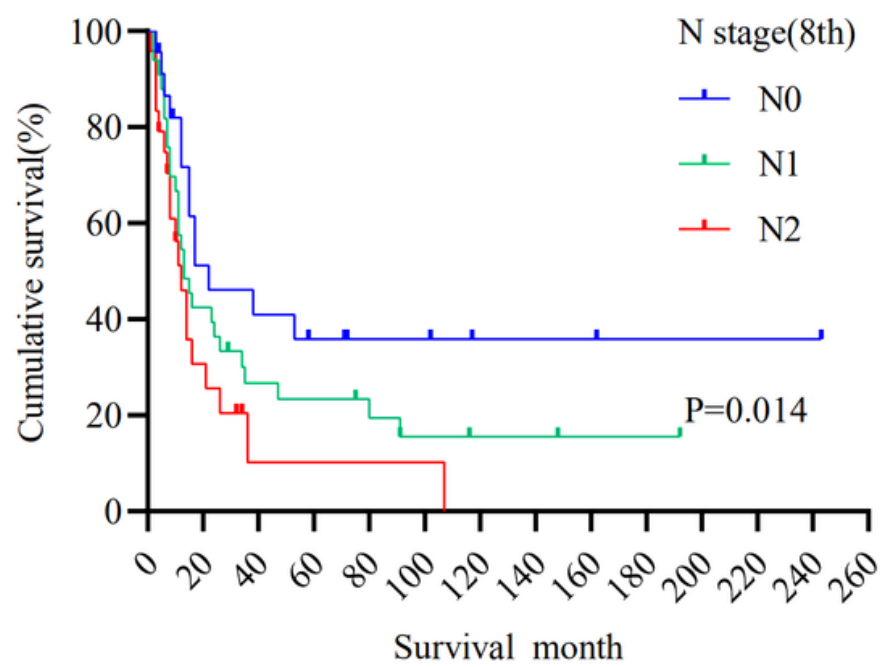

Figure 6

Kaplan-Meier of overall survival analysis of patients with No lymph node metastasis (LNM) $\otimes 1$ to 3 LNM and 4 LNM stratified by TNLE $<8$ or at least 8 . 


\section{TLNE}

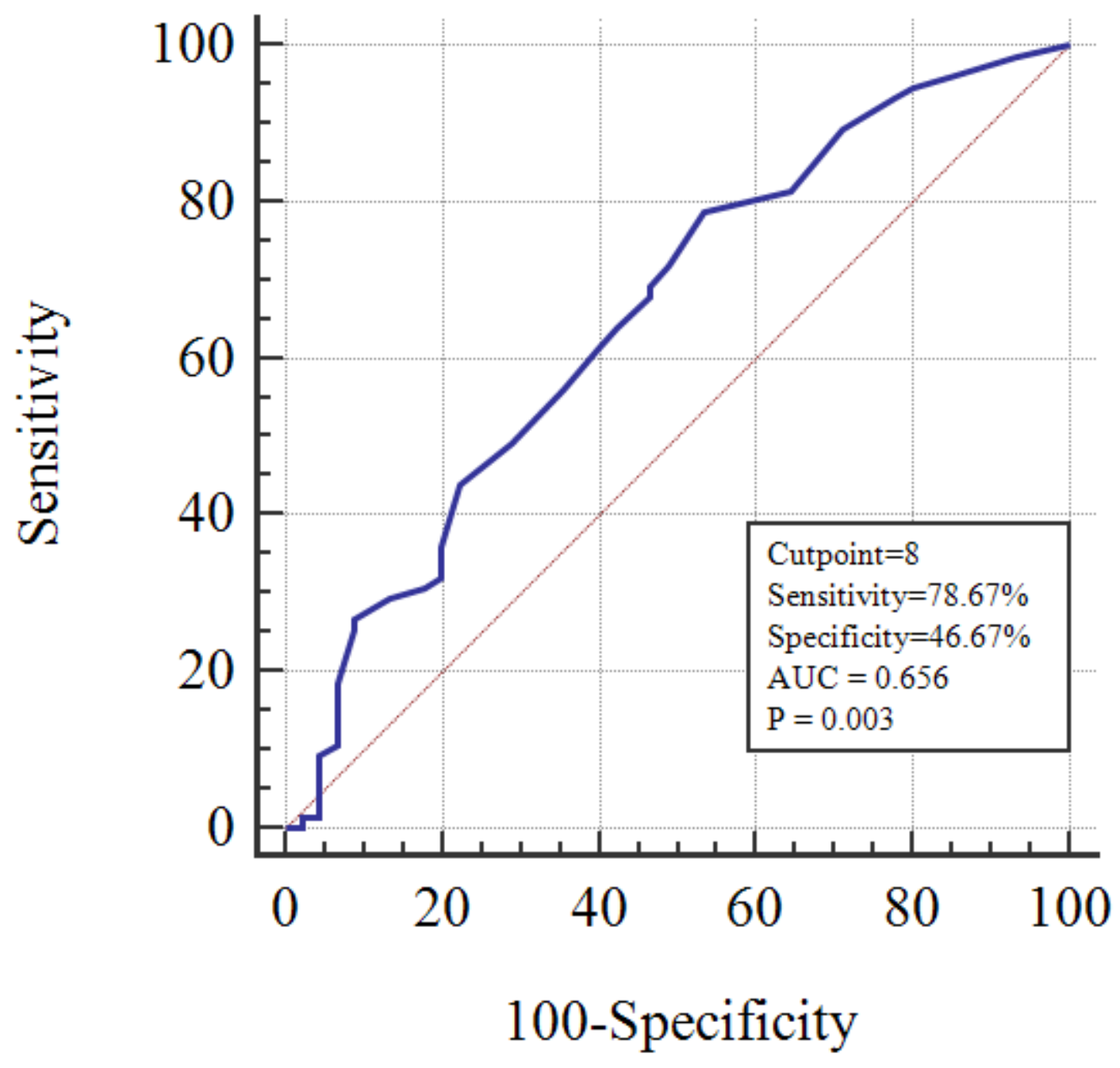

Figure 7

Receiver-operating characteristic (ROC) analysis illustrated the optimal cutoff value of the total number of lymph nodes examined. 